\title{
Dukungan Orang Tua dengan Perilaku Cuci Tangan dan Gosok Gigi pada Anak di TK ABA Kepiton, Kulon Progo
}

\author{
Isman Susanto ${ }^{1}$, Nita Fitriana² \\ 1,2,Sekolah Tinggi Ilmu Kesehatan Alma Ata Yogyakarta \\ Jalan Ringroad Barat Daya No 1 Tamantirto, Kasihan, Bantul, Yogyakarta
}

\begin{abstract}
Abstrak
Masa kanak-kanak merupakan masa yang sangat rentan terhadap penyakit karena kurangnya sanitasi yang efektif dan kebersihan yang buruk. Membiasakan cuci tangan dan gosok gigi merupakan bagian dari perilaku kesehatan yang perlu ditanamkan untuk mencegah penyakit. Orang tua memiliki peran sangat penting dalam memberikan dukungan perawatan atau pemeliharaan kesehatan anaknya. Tujuan penelitian untuk mengetahui hubungan antara dukungan orang tua dengan perilaku cuci tangan dan gosok gigi pada anak di TK ABA Kepiton, Kulon Progo. Metode penelitian kuantitatif induktif dengan pendekatan penelitian cross sectional. Populasi penelitian ini seluruh anak beserta orang tua dari anak yang bersekolah di TK ABA Kepiton, Kulon Progo berjumlah 37 anak. Pengambilan sampel dengan metode total sampling, jumlah sampel yang sesuai kriteria sebanyak 35 anak. Analisa data dengan Fisher's Exact Test. Hasil penelitian menunjukkan ada hubungan antara dukungan orang tua dengan perilaku cuci tangan anak, nilai $p=0,009$ $(p<0,05)$ dan tidak ada hubungan antara dukungan orang tua dengan perilaku gosok gigi anak, nilai $p=0,292$ $(p>0,05)$. Simpulan ada hubungan antara dukungan orang tua dengan perilaku cuci tangan anak dan tidak ada hubungan antara dukungan orang tua dengan perilaku gosok gigi anak.
\end{abstract}

Kata Kunci: cuci tangan, dukungan orang tua, gosok gigi

\section{Parents Support with Hands Washing and Teeth Brushing Behaviors of Children at Kindergarten ABA Kepiton, Kulon Progo}

\begin{abstract}
Childhood is a time that very susceptible to various diseases due to a less of affective sanitation and poor hygiene. Hands washing and teeth brushing behavior are part of the health behaviors that need to be invested to prevent the diseases. Parents have important role in providing support and maintaining their children's health care. Objective of this research was to know a relationship between parents support with hands washing and teeth brushing behaviors among children in Kindergarten ABA Kepiton, Kulon Progo. This research was a Quantitative inductive research with cross sectional study approach. The Population were all of children and parents of children attending in kindergarten ABA Kepiton, Kulon Progo which consisted of 37 childrens. With a total sampling method, the number of samples was meet inclusion and exclusion criteria were 35 childrens. Analysis of the data used Fisher's Exact Test. Results of Fisher's Exact Test showed that there was relationship between parents support and hands washing behavior in children, $p$-value $=0.009(p<0.05)$ and there was no relationship between parents support and teeth brushing behavior in children, $p$-value $=0.292$ $(p>0.05)$. In conclusion, there was a relationship between parents support and hands washing behavior in children and there was no relationship between parents support and teeth brushing behavior in children.
\end{abstract}

Keywords: hands washing, parents support, teeth brushing

Info Artikel:

Artikel dikirim pada 17 Januari 2015

Artikel diterima pada 17 Januari 2015 


\section{PENDAHULUAN}

Kehidupan pada masa anak-anak merupakan masa yang sangat rentan terhadap berbagai penyakit yang disebabkan oleh kurangnya sanitasi yang efektif dan kebersihan yang buruk. Lebih dari 5.000 anak dibawah usia lima tahun meninggal setiap hari akibat penyakit diare yang sebagian disebabkan oleh air yang tidak aman, kurangnya akses terhadap fasilitas sanitasi dasar dan kebersihan yang buruk(1). Selain itu, permasalahan kerusakan gigi pada anak juga merupakan masalah gigi nomor satu yang terjadi diantara anak prasekolah(2).

Penyakit diare maupun penyakit lainnya seperti infeksi saluran pernafasan yaitu pneumonia dan penyakit lainnya, termasuk infeksi mata utamanya trachoma sebenarnya dapat dicegah dengan cara membiasakan melakukan cuci tangan dengan air dan sabun(3). Sementara itu, kerusakan gigi seperti karies pada gigi anak dapat dicegah dengan melakukan gosok gigi secara benar (setelah makan dan sebelum tidur), karena gosok gigi secara benar merupakan dasar program higiene mulut yang efektif $(4,5)$.

Faktanya perilaku cuci tangan dan gosok gigi anak di Indonesia masih rendah. Berdasarkan data Riskesdas 2007, perilaku anak 10-14 tahun yang melakukan cuci tangan secara benar hanya $17,2 \%$, sedangkan untuk perilaku gosok gigi secara benar anak usia 10-14 tahun hanya 6,2\%. Dalam hal waktu menyikat gigi, perilaku menyikat gigi anak usia 1014 tahun sesudah makan pagi hanya $11,8 \%$ dan menyikat gigi sebelum tidur hanya $25,0 \%(6)$.

Perilaku kesehatan pada anak ini sebenarnya dapat ditimbulkan dengan melakukan kebiasaan kesehatan. Kebiasaan-kebiasaan kesehatan pada masa kanak-kanak terbentuk karena pengaruh sikap dan tingkah laku orang tua(7). Anak-anak merupakan masa dimana masih dalam taraf memerlukan bimbingan yang ketat. Orang tua sebagai bagian dari keluarga memiliki peran yang sangat penting dalam tahap perawatan atau pemeliharaan kesehatan anggota keluarganya $(8,9)$.

Berdasarkan studi pendahuluan terhadap 10 anak dan 10 orang tua anak di TKABA Kepiton, Kulon Progo, didapatkan bahwa $90 \%$ anak melakukan cuci tangan sebelum makan, namun $40 \%$ diantaranya belum rutin cuci tangan pakai sabun. Hanya $40 \%$ melakukan cuci tangan setelah bermain, dan 50\% melakukan cuci tangan setelah Buang Air Besar (BAB). Sementara untuk perilaku gosok gigi anak, didapat $60 \%$ anak melakukan gosok gigi pada pagi hari dan hanya $40 \%$ yang melakukan gosok gigi sebelum tidur. Dukungan yang diberikan orang tua terhadap perilaku cuci tangan dan gosok gigi anak, didapat $20 \%$ orang tua menyuruh anak sikat gigi hanya 1 kali sehari pada pagi hari dan $80 \%$ orang tua menyuruh anak sikat gigi 2 kali sehari pada pagi dan malam hari, namun belum rutin pada malam hari. $50 \%$ orang tua menyuruh anak mencuci tangan sebelum makan, setelah bermain, setelah BAB dan $50 \%$ sisanya menyuruh cuci tangan hanya sebelum makan atau setelah bermain atau setelah BAB.

Berdasarkan uraian di atas, peneliti tertarik untuk mengetahui apakah ada hubungan antara dukungan orang tua dengan perilaku cuci tangan dan gosok gigi pada anak di TK ABA Kepiton, Kulon Progo.

\section{BAHAN DAN METODE}

Jenis penelitian ini merupakan penelitian kuantitatif induktif dengan pendekatan cross sectional yang dilaksanakan pada tanggal 1-7 Februari 2015 bertempat di TK ABA Kepiton, Kulon Progo. Metode pengambilan sampel dengan total sampling. Jumlah sampel yang memenuhi kriteria sebanyak 35 anak beserta orang tua dari anak. Variabel bebas adalah dukungan orang tua dan variabel terikat adalah perilaku cuci tangan anak dan perilaku gosok gigi anak. Analisis univariat dengan menggunakan tabel frekuensi, analisis bivariat dengan uji Fisher's Exact Test. Instrumen yang digunakan dalam penelitian ini adalah kuesioner yang dibuat oleh peneliti sendiri berdasarkan literatur terkait.Kuesioner terdiri dari 2 macam, yaitu kuesioner dukungan orang tua dan kuesioner perilaku cuci tangan dan gosok gigi anak. Uji validitas dan realibilitas kuesioner peneliti lakukan di TK ABA Dekso yang berada masih dalam satu daerah dengan jarak sekitar 2 km dari TK ABA Kepiton. Peneliti memilih TK ABA Dekso sebagai tempat uji instrumen karena peneliti mempertimbangkan karakteristik yang hampir sama dengan tempat penelitian yang masih terletak dalam satu daerah. Uji validitas dan realibilitas dilakukan pada 26 anak beserta orang tua anak di TK ABA Dekso. Hasil hitung didapatkan bahwa seluruh kuesioner mempunyai nilai Cronbach Alpha $>0,7$, maka seluruh kuesioner tersebut hasilnya realibel.

\section{HASIL DAN BAHASAN}

\section{Analisis Univariat}

\section{Karakteristik Responden Anak}

Berdasarkan Tabel 1 dapat diketahui bahwa sebagian besar anak berumur $5-<6$ tahun yaitu 16 anak, sebagian besar berjenis kelamin perempuan yaitu 19 anak, dan paling banyak anak tinggal di dusun Banjarasri sebanyak 23 anak. 
Tabel 1. Distribusi Frekuensi Karakteristik Responden Anak

\begin{tabular}{lcc}
\hline \multicolumn{1}{c}{ Karakteristik } & $\mathbf{n}$ & $\%$ \\
\hline Umur (Tahun) & & \\
$\quad<4$ & 2 & 5,8 \\
$4-<5$ & 6 & 17,1 \\
$5-<6$ & 16 & 45,7 \\
6-7 & 11 & 31,4 \\
Jenis Kelamin & & \\
$\quad$ Laki-Laki & 16 & 45,7 \\
$\quad$ Perempuan & 19 & 54,3 \\
Tempat Tinggal (Dusun) & & \\
$\quad$ Banjararum & 7 & 20,0 \\
$\quad$ Banjarasri & 23 & 65,7 \\
$\quad$ Banjarharjo & 5 & 14,3 \\
Total & 35 & 100 \\
\hline
\end{tabular}

Sumber: Data Primer 2015

\section{Karakteristik Responden Orang Tua}

Tabel 2 memperlihatkan bahwa sebagian besar orang tua berumur 30-39 tahun yaitu 41 orang, sebagian besar tingkat pendidikan orang tua menempuh jenjang pendidikan SMA yaitu 46 orang, dan paling banyak dari orang tua bekerja sebagai petani yaitu 20 orang.

\section{Dukungan Orang Tua Terhadap Perilaku Cuci Tangan dan Gosok Gigi anak.}

Berdasarkan Tabel 3 dapat diketahui bahwa rata-rata orang tua mendukung terhadap perilaku cuci tangan anak yaitu 32 orang dibanding yang tidak mendukung hanya 3 orang dan rata-rata orang tua juga mendukung terhadap perilaku gosok gigi anak yaitu 30 orang dibanding yang tidak mendukung hanya 5 orang. Pada perilaku anak, sebagian besar anak berperilaku baik dalam hal perilaku mencuci tangan yaitu 27 anak dan sebaliknya sebagian besar anak berperilaku tidak baik dalam hal perilaku menyikat gigi yaitu 25 anak.

Hasil tabulasi silang pada Tabel 4 dengan analisis bivariat menggunakan uji Fisher's Exact Test antara dukungan orang tua dengan perilaku cuci tangan anak, didapatkan nilai $p=0,009<0,05$ maka $\mathrm{H}_{0}$ ditolak atau ada hubungan yang bermakna antara dukungan orang tua dengan perilaku cuci
Tabel 2. Distribusi Frekuensi Karakteristik Responden Orang Tua

\begin{tabular}{lcc}
\hline \multicolumn{1}{c}{ Karakteristik } & $\mathbf{n}$ & $\mathbf{\%}$ \\
\hline Umur (Tahun) & & \\
$20-29$ & 10 & 14,3 \\
$30-39$ & 41 & 58,6 \\
$40-50$ & 19 & 27,1 \\
Pendidikan & & \\
SD & 2 & 2,9 \\
SMP & 15 & 21,4 \\
SMA & 46 & 65,7 \\
D3 & 2 & 2,9 \\
S1 & 5 & 7,1 \\
Pekerjaan & & \\
Tidak Bekerja & 1 & 1,5 \\
IRT & 15 & 21,4 \\
Buruh & 3 & 4,3 \\
Petani & 20 & 28,6 \\
Perangkat Desa & 1 & 1,4 \\
Karyawan Swasta & 8 & 11,4 \\
Wiraswasta & 17 & 24,3 \\
PNS & 5 & 7,1 \\
Total & 70 & 100 \\
\hline
\end{tabular}

Sumber: Data Primer 2015

Tabel 3. Distribusi Frekuensi Variabel Penelitian

\begin{tabular}{lcc}
\hline \multicolumn{1}{c}{ Variabel } & $\mathbf{n}$ & $\%$ \\
\hline Dukungan orang tua pada perilaku cuci & & \\
tangan anak & 32 & 91,4 \\
$\quad$ Mendukung & 3 & 8,6 \\
$\quad$ Tidak Mendukung & & \\
Dukungan orang tua pada perilaku gosok & & \\
gigi anak & 30 & 85,7 \\
$\quad$ Mendukung & 5 & 14,3 \\
$\quad$ Tidak Mendukung & & \\
Perilaku cuci tangan anak & & \\
$\quad$ Baik & 27 & 77,1 \\
$\quad$ Tidak Baik & 8 & 22,9 \\
Perilaku gosok gigi anak & & \\
$\quad$ Baik & 10 & 28,6 \\
$\quad$ Tidak Baik & 25 & 71,4 \\
Total & 35 & 100 \\
\hline
\end{tabular}

Sumber: Data Primer 2015

tangan anak. Tingkat keterpaparan informasi dan peralatan mencuci tangan dalam kegiatan rutin mencuci tangan memberikan dampak positif 2 kali lipat pada perilaku mencuci tangan anak ketika di

Tabel 4. Tabulasi Silang Dukungan Orang Tua dengan Perilaku Cuci Tangan dan Gosok Gigi Anak

\begin{tabular}{|c|c|c|c|c|c|c|c|c|c|c|}
\hline \multirow{3}{*}{ Variabel } & \multicolumn{4}{|c|}{ Perilaku cuci tangan } & \multirow{3}{*}{$p$-value } & \multicolumn{4}{|c|}{ Perilaku gosok gigi } & \multirow{3}{*}{$p$-value } \\
\hline & \multicolumn{2}{|c|}{ Baik } & \multicolumn{2}{|c|}{ Tidak Baik } & & \multicolumn{2}{|c|}{ Baik } & \multicolumn{2}{|c|}{ Tidak Baik } & \\
\hline & $\mathbf{n}$ & $\%$ & $\mathbf{n}$ & $\%$ & & $\mathbf{n}$ & $\%$ & $\mathbf{n}$ & $\%$ & \\
\hline \multicolumn{11}{|c|}{ Dukungan Orang Tua } \\
\hline Mendukung & 27 & 77,1 & 5 & 14,3 & 0,009 & 10 & 28,6 & 20 & 57,1 & 0,292 \\
\hline Tidak Mendukung & 0 & 0,0 & 3 & 8,6 & & 0 & 0,0 & 5 & 14,3 & \\
\hline Total & 27 & 77,1 & 8 & 22,9 & & 10 & 28,6 & 25 & 71,4 & \\
\hline
\end{tabular}

Sumber Data Primer 2015 
rumah. Hal ini membuktikan bahwa orang tua yang memberikan dukungan yang baik dalam bentuk dukungan informasional (bantuan informasi) maupun dukungan instrumental/peralatan mencuci tangan dapat meningkatkan perilaku cuci tangan anak(10).

Orang tua merupakan bagian dalam keluarga yang merupakan guru yang utama bagi pembelajaran suatu perilaku, perasaan dan pikiran seorang anak(11). Orang tua yang memberikan dukungan yang baik dengan membiasakan anak mencuci tangan maka dapat terbentuk perilaku mencuci tangan anak. Perilaku dapat terbentuk dengan kebiasaan atau conditioning. Pembentukan perilaku dengan cara membiasakan diri berperilaku sesuai dengan yang diharapkan maka akan terbentuk suatu perilaku tersebut, misalnya membiasakan untuk bangun pagi, gosok gigi, cuci tangan, dan sebagainya(12).

Berdasarkan hasil tabulasi silang Tabel 4 antara antara dukungan orang tua dengan perilaku gosok gigi anak didapatkan nilai $p=0,292>0,05$ maka $\mathrm{H}_{0}$ diterima atau tidak ada hubungan yang bermakna antara dukungan orang tua dengan perilaku gosok gigi anak. Hasil dari data tabulasi silang menggambarkan bahwa orang tua rata-rata mendukung tetapi banyak perilaku gosok gigi anak yang tidak baik. Hal ini dapat disebabkan karena adanya faktor lain. Penelitian lain menunjukkan bahwa ada faktor kendala luar yang berasal dari anak itu sendiri yang dilaporkan oleh orang tua, yaitu 39 dari 44 orang tua melaporkan bahwa anak mereka tidak kooperatif saat akan dibantu gosok gigi(13). Perilaku anak yang tidak kooperatif ini timbul saat gosok gigi malam hari.

Tabel 5 menggambarkan bahwa ditinjau dari segi waktu, sebagian besar anak mencuci tangan sebelum makan yaitu kadang-kadang sebanyak 18 anak, sebagian besar selalu melakukan cuci tangan setelah BAB sebanyak 24 anak, dan kebanyakan selalu mencuci tangan setelah bermain sebanyak 20 anak. Pada perilaku gosok gigi, rata-rata anak selalu menggosok gigi pada pagi hari dan kebanyakan kadang-kadang menggosok gigi malam hari yaitu 22 anak, bahkan ada yang tidak pernah gosok gigi malam sebanyak 8 .

Perilaku gosok gigi anak di TK ABA Kepiton banyak yang tidak baik pada saat gosok gigi malam hari. Kebanyakan orang tua menyadari pentingnya menyikat gigi untuk anak-anak mereka, khususnya menyikat gigi sebelum tidur malam dan pentingnya memberikan pengawasan pada anak. Namun disisi lain, banyak orang tua melaporkan adanya kesulitan dalam mencapai waktu menyikat gigi pada malam hari yang sering disebabkan karena anak sudah mengantuk atau telah jatuh tertidur segera setelah makan malam(14).
Tabel 5. Distribusi Frekuensi Menurut Waktu Cuci Tangan dan Gosok Gigi Anak

\begin{tabular}{|c|c|c|}
\hline Waktu & $\mathbf{n}$ & $\%$ \\
\hline \multicolumn{3}{|l|}{ Waktu Cuci Tangan } \\
\hline \multicolumn{3}{|l|}{ Sebelum makan } \\
\hline Selalu & 17 & 48,6 \\
\hline Kadang-Kadang & 18 & 51,4 \\
\hline Tidak Pernah & 0 & 0,0 \\
\hline \multicolumn{3}{|l|}{ Setelah BAB } \\
\hline Selalu & 24 & 68,6 \\
\hline Kadang-Kadang & 11 & 31,4 \\
\hline Tidak Pernah & 0 & 0,0 \\
\hline \multicolumn{3}{|l|}{ Setelah bermain } \\
\hline Selalu & 20 & 57,1 \\
\hline Kadang-Kadang & 14 & 40,0 \\
\hline Tidak Pernah & 1 & 2,9 \\
\hline \multicolumn{3}{|l|}{ Waktu gosok gigi } \\
\hline \multicolumn{3}{|l|}{ Pagi hari } \\
\hline Selalu & 31 & 88,6 \\
\hline Kadang-Kadang & 4 & 11,4 \\
\hline Tidak Pernah & 0 & 0,0 \\
\hline \multicolumn{3}{|l|}{ Malam hari } \\
\hline Selalu & 5 & 14,2 \\
\hline Kadang-Kadang & 22 & 62,9 \\
\hline Tidak Pernah & 8 & 22,9 \\
\hline Total & 35 & 100 \\
\hline
\end{tabular}

Sumber: Data Primer 2015

Perilaku tidak patuh seperti mengamuk, diantara anak prasekolah juga ditemukan menjadi penghalang yang paling umum dan penyulit dalam hal menyikat gigi yang dilaporkan oleh hampir semua ibu. Berbagai hal yang menyebabkan perilaku tidak patuh ini antara lain anak secara umum tidak suka menyikat gigi, anak menolak untuk membuka mulut saat akan dibantu menyikat gigi oleh ibu mereka, bahkan penolakan anak untuk menyikat gigi malam hari ini dengan cara anak tidur lebih awal untuk mencegah orang tua menyikat gigi mereka(15).

Anak-anak pada tahapan umur prasekolah merupakan masa atau tahap perkembangan praoperasional. Pemikiran anak masih terbatas karena mereka cenderung egosentris atau memikirkan dirinya sendiri. Menurut Piaget, berpikir egosentris adalah salah satu keterbatasan yang dihadapi oleh anak-anak dalam tahap praoperasional. Anak-anak memiliki keterbatasan dalam hal ketidakmampuan untuk memahami lebih dari satu aspek masalah pada waktu yang sama. Anak akan cenderung memakai intuisi, dan tidak dengan logika dalam menyelesaikan masalah(16). Hal ini jika dikaitkan dengan penolakan anak saat gosok gigi malam hari, terjadi karena pemikiran egosentris anak yang belum bisa berpikir dengan logika mengenai kegiatan menyikat gigi malam hari, sehingga anak akan cenderung menolak saat akan dibantu oleh orang tua mereka untuk gosok gigi malam hari dengan menunjukkan perilaku tidak kooperatif. 


\section{SIMPULAN DAN SARAN}

Berdasarkan hasil penelitian ini dapat disimpulkan ada hubungan yang bermakna antara dukungan orang tua dengan perilaku cuci tangan anak ( $p$-value $=0,009$ ), dan tidak ada hubungan antara dukungan orang tua dengan perilaku gosok gigi anak $(p$-value $=0,292)$. Oleh karena itu, tenaga kesehatan dapat mengoptimalkan peran dan dukungan dari orang tua untuk membiasakan anak pada perilaku kesehatan yang baik.

\section{DAFTAR RUJUKAN}

1. UNICEF. In The Fight To Save Children's Lives, Washing Hands Takes Centre Stage [internet]. 2008 [cited 2014 Nov 17]. Available from: http:// www.unicef.org/m edia/ media45956.html.

2. American Academy of Pediatrics. Dental Health: Keeping Your Child's Teeth Healthy [internet]. 2009 [cited 2014 Nov 20]. Available from: .

3. Kementerian Kesehatan RI. Hari Cuci Tangan Pakai Sabun Sedunia 2010: Perilaku Sederhana Berdampak Luar Biasa. Kemenkes R I [internet]. 2010 [cited 2014 Nov 9]. Available from: http:// www.depkes.go.id/article/view/1260/hari-cuci tanganpakai-sabun-sedunia-2010-perilakuseder hana-berdampakluarbiasa .html\#sth ash. q4wT9RgT.dpuf.

4. Potter dan Perry. Buku Ajar Fundamental Keperawatan Konsep, Teori dan Praktik. vol.4. 2nd ed. Jakarta: EGC; 2006.

5. Kementerian Kesehatan RI. Riset Kesehatan Dasar (Riskesdas) 2013. Jakarta: Kemenkes RI; 2013.
6. Departemen Kesehatan RI. Riset Kesehatan Dasar (Riskesdas) 2007. Jakarta: Depkes RI; 2008.

7. Suryani, Eko, Hesty W. Psikologi Ibu dan Anak. Yogyakarta: Fitramaya; 2008.

8. Friedman, Marilyn M. Keperawatan Keluarga Teori dan Praktek. Jakarta: EGC; 1998.

9. Efendi, Ferry, Makhfudli. Keperawatan Kesehatan Komunitas Teori dan Praktek dalam Keperawatan. Jakarta: Salemba Medika; 2009.

10. Lestari, Asri P. Pengaruh Kegiatan Rutin Mencuci Tangan Di Sekolah dengan Perilaku Mencuci Tangan Anak Prasekolah Usia 4-6 Tahun Di TK Islam Terpadu As Salam Kota Malang. BIMIKI. 2013;2(1).

11. Wong, Donna L, David W, et al. Buku ajar Keperawatan Pediatrik. Vol. 1, 6th ed. Jakarta: EGC; 2009.

12. Notoatmodjo, Soekidjo. Pendidikan dan Perilaku Kesehatan. Jakarta: Rineka Cipta; 2003.

13. Huebner, Collen E, Christine AR. Behavioral Determinants of Brushing Young Children's Teeth: Implications for Anticipatory Guidance. Pediatr Dent. 2010; 32(1):48-55.

14. Naidu, Rahul, June N, Maarit F. Oral Health Care of Preschool Children in Trinidad: A Qualitative Study of Parents and Caregivers. BMC Oral Health. 2012;12:27

15. Elison, Sarah, Sarah N, et al. Maternally Barriers to and Facilitators of Establishing and Maintaining Tooth-Brushing Routines with Infants and Preschoolers. International Journal of Enviromental Research and Public Health. 2014;11:6808-6826.

16. Wuryani, Sri E. Psikologi Pendidikan. Jakarta: Gramedia; 2002. 